\title{
The Preventive Effect of Oxytocin to Cisplatin-Induced Neurotoxicity: An Experimental Rat Model
}

\author{
Tulay Akman, ${ }^{1}$ Levent Akman, ${ }^{2}$ Oytun Erbas, ${ }^{3}$ Mustafa Cosan Terek, \\ Dilek Taskiran, ${ }^{3}$ and Aydin Ozsaran ${ }^{2}$ \\ ${ }^{1}$ Division of Medical Oncology, Tepecik Education and Research Hospital, Gaziler Caddesi No. 468, Yenisehir, 35110 Izmir, Turkey \\ ${ }^{2}$ Department of Obstetrics and Gynecology, Faculty of Medicine, Ege University, Izmir, Turkey \\ ${ }^{3}$ Department of Physiology, Faculty of Medicine, Ege University, Izmir, Turkey
}

Correspondence should be addressed to Tulay Akman; tulaytuzel@gmail.com

Received 31 August 2014; Accepted 13 October 2014

Academic Editor: Arianna Scuteri

Copyright (C) 2015 Tulay Akman et al. This is an open access article distributed under the Creative Commons Attribution License, which permits unrestricted use, distribution, and reproduction in any medium, provided the original work is properly cited.

\begin{abstract}
Peripheral neurotoxicity is a frequent dose-limiting side effect of the chemotherapeutic agent cisplatin. This study was conducted to investigate the preventive effect of oxytocin (OT) on cisplatin-induced neurotoxicity in rats. Forty-four adult female rats were included in the study. Thirty-six rats were administered intraperitoneally (i.p.) single dose cisplatin $10 \mathrm{mg} / \mathrm{kg}$ and divided in to 3 groups. The first group $(n=12)$ received saline i.p., whereas the second group $(n=12)$ and the third group $(n=12)$ were injected with $80 \mu \mathrm{g} / \mathrm{kg}$ and $160 \mu \mathrm{g} / \mathrm{kg}$ OT, respectively, for 10 days. The remaining 8 rats served as the control group. Electromyography (EMG) studies were recorded and blood samples were collected for the measurement of plasma lipid peroxidation (malondialdehyde; MDA), tumor necrosis factor (TNF)- $\alpha$, and glutathione (GSH) levels. EMG findings revealed that compound muscle action potential amplitude was significantly decreased and distal latency was prolonged in the nontreated cisplatin-injected rats compared with the control group $(P<0.005)$. Also, nontreated cisplatin-injected rats showed significantly higher TNF- $\alpha$ and MDA levels and lower GSH level than control group. The administration of OT significantly ameliorated the EMG alterations, suppressed oxidative stress and inflammatory parameters, and increased antioxidative capacity. We suggest that oxytocin may have beneficial effects against cisplatin-induced neurotoxicity.
\end{abstract}

\section{Introduction}

Cisplatin (cis-diamminedichloroplatinum) is the first antineoplastic agent which has been used in cancer treatment. It is used for the treatment of various solid tumors such as lung, ovary, testis, bladder, head and neck, and cervical and endometrial cancers [1]. Autotoxicity, neurotoxicity, and nephrotoxicity are the dose-limiting side effects of cisplatin [2]. Cisplatin-induced peripheral neuropathy is a frequent adverse effect leading to a dose reduction or the early cessation of chemotherapy, thereby potentially impacting patient survival [3]. Peripheral neuropathy is characterized with decreased neural transmission rate, loss of vibration and position senses, tingling paresthesia, dysesthesia, loss of tendon reflexes, tremor, ataxia, and muscle weakness [4-6]. The side effects of the cisplatin on both human and animal nervous systems are demonstrated with electrophysiological and histopathological experiments [5, 7-9]. Oxidative stress, DNA damage, and inflammatory cytokines play major role in the mechanism of cisplatin-induced cytotoxicity [10]. On the other hand, pathophysiological mechanisms of cisplatininduced neurotoxicity include oxidative damage, inflammation, mitochondrial dysfunction, DNA damage, and apoptotic cell death in the nervous system [11, 12].

Since cisplatin-induced neurotoxicity is the major doselimiting adverse effect of cisplatin, there are numerous studies dealing with this issue [9]. The efficacy of antioxidative treatments on preventing neurotoxicity associated with platinumbased chemotherapeutic regimens has been demonstrated in several studies $[9,13,14]$. Antioxidants such as resveratrol, curcumin, vitamin E, thiamine pyrophosphate, and melatonin have been used to reduce this type of toxicity $[9,13-17]$.

Oxytocin (OT) is a neurohypophyseal nonapeptide synthesized at the paraventricular and supraoptic nuclei of the 
hypothalamus. Although OT is essential for the milk letdown reflex, studies in OT-deficient mice show that OT's role in parturition is obviously more complex [18]. OT exerts its effects via G-protein-coupled receptors, which are expressed abundantly in the central and peripheral nervous systems. Moreover, OT plays a role in the endocrine and paracrine activities such as various sexual and maternal behaviors, social recognition, aggression, neuromodulation, cognition, and tolerance development [19]. In addition, the impact of OT on wound healing as an immunomodulatory and antiinflammatory agent, which regulates the anti-inflammatory and proinflammatory cytokines, has also been shown [19-22].

As oxidative stress and inflammation play the major role in the pathogenesis of cisplatin-induced neurotoxicity and the antioxidant/anti-inflammatory effects of OT are well known, we hypothesized that OT may be beneficial in preventing the cisplatin-induced neurotoxicity. Therefore, we aimed to evaluate the therapeutic potential of OT in cisplatininduced neurotoxicity by electromyography (EMG) recordings and measuring TNF- $\alpha$ levels, which is an important inflammation marker for lipid peroxidation and antioxidative capacity.

\section{Materials and Methods}

2.1. Animals. In this study 44 female Sprague-Dawley albino mature rats, weighing 200-220 g, were used. Animals were fed ad libitum and housed in pairs in steel cages, having a temperature-controlled environment $\left(22 \pm 2^{\circ} \mathrm{C}\right)$ with $12 \mathrm{~h}$ light/dark cycles. The experimental procedures were approved by the Animal Research Committee in Ege University. All animal studies are strictly conformed to the animal experiment guidelines of the Committee for Human Care.

2.2. Experimental Procedure. Of the 44 rats included, 36 were injected with a single dose of $10 \mathrm{mg} / \mathrm{kg}$ cisplatin i.p. to induce neurotoxicity development [16]. The drug-administered rats were divided into 3 groups. The first group $(n=12)$ received $1 \mathrm{~mL} / \mathrm{kg} \% 0.9 \mathrm{NaCl}$ (saline) i.p. for 10 days, whereas the second group $(n=12)$ and the third group $(n=12)$ were injected with $80 \mu \mathrm{g} / \mathrm{kg}$ and $160 \mu \mathrm{g} / \mathrm{kg} \mathrm{OT}$, respectively, for the same duration of time. The remaining 8 rats served as the control group and did not receive any treatment. Five rats from the saline group and 3 rats from the OT-injected groups died during the study.

\subsection{Electrophysiological Recordings. Electromyographic} (EMG) studies were performed 10 days after the injection of cisplatin. EMG recordings were obtained 3 times from the right sciatic nerve, stimulated supramaximally (intensity $10 \mathrm{~V}$, duration $0.05 \mathrm{~ms}$, frequency $1 \mathrm{~Hz}$, in the range of $0.5-$ $5000 \mathrm{~Hz}, 40 \mathrm{kHz} / \mathrm{s}$ with a sampling rate) by a bipolar subcutaneous needle stimulation electrode (BIOPAC Systems, Inc, Santa Barbara, CA, USA) from the sciatic notch. Compound muscle action potentials (CMAP) were recorded from 2-3 interosseous muscles by unipolar platinum electrodes. Data were evaluated by Biopac Student Lab Pro version 3.6.7 software (BIOPAC Systems, Inc) where distal latency and amplitude of CMAP were used as the parameters. During the EMG recordings, rectal temperatures of the rats were monitored by a rectal probe (HP Viridia 24-C; HewlettPackard Company, Palo Alto, CA, USA) and the body temperature of each rat was kept at approximately $36-37^{\circ} \mathrm{C}$ by a heating pad. Following the EMG recordings, animals were euthanized and blood samples were collected with cardiac puncture for biochemical measurements. These samples were centrifuged at $3000 \mathrm{rpm}$ for 10 minutes at room temperature and stored at $-20^{\circ} \mathrm{C}$ until they are assayed.

2.4. Measurement of Lipid Peroxidation. Lipid peroxidation was determined in the plasma samples by measuring the malondialdehyde (MDA) levels as thiobarbituric acid reactive substances (TBARS). Briefly, trichloroacetic acid and TBARS reagent were added to the plasma samples, then mixed, and incubated at $100^{\circ} \mathrm{C}$ for $60 \mathrm{~min}$. After cooling on ice, the samples were centrifuged at $3000 \mathrm{rpm}$ for 20 minutes and the absorbance of the supernatant was read at $535 \mathrm{~nm}$. MDA levels were expressed as $\mathrm{nM}$ and tetraethoxypropane was used for calibration [23].

2.5. Measurement of Plasma Glutathione Levels. Glutathione (GSH) content in the plasma samples was measured spectrophotometrically according to Ellman's method [24]. In this method, thiols interact with 5,5'-dithiobis-(2-nitrobenzoic acid) (DTNB) and form a colored anion with maximum peak at $412 \mathrm{~nm}$. GSH levels were calculated from the standard calibration curve and expressed as $\mu \mathrm{M}$.

2.6. Measurement of Plasma Tumor Necrosis Factor Alpha(TNF-) $\alpha$ Level. Plasma TNF- $\alpha$ level was measured with commercially available enzyme-linked immunosorbent assay (ELISA) kit (Biosciences). The plasma samples were diluted $1: 2$ and TNF- $\alpha$ was determined in duplicate according to the manufacturer's guide. The detection range for the TNF- $\alpha$ assay was $<2 \mathrm{pg} / \mathrm{mL}$.

2.7. Statistical Analysis. Statistical analysis was performed with the Statistical Package for Social Sciences (SPSS) version 15.0 for Windows. Parametric variables were compared with Student's $t$-test and analysis of variance, whereas nonparametric variables were compared with Mann-Whitney $U$ test. In addition, Shapiro-Wilk test was used for parametric-nonparametric differentiation. Results are presented as "mean \pm standard error of mean (SEM)." A $P<0.05$ was accepted as statistically significant.

\section{Results}

3.1. Electromyographic Results. Table 1 shows the alterations in EMG recordings in all groups. CMAP amplitude was significantly lower and the latency was significantly prolonged in the nontreated cisplatin-injected rats, compared to the control group $(P<0.005)$. When the treatment groups were compared, latency was shortened in both OT groups compared to the nontreated cisplatin-injected rats; however, the difference did not reach statistically significant level. 
TABLE 1: The alterations in electromyographic recordings in all groups.

\begin{tabular}{lcccc}
\hline & Normal control & Cisplatin + saline & Cisplatin $+80 \mu \mathrm{g} / \mathrm{kg}$ oxytocin & Cisplatin $+160 \mu \mathrm{g} / \mathrm{kg}$ oxytocin \\
\hline CMAP latency $(\mathrm{ms})$ & $2.44 \pm 0.02$ & $2.58 \pm 0.02^{*}$ & $2.53 \pm 0.05$ & $2.51 \pm 0.03$ \\
CMAP amplitude $(\mathrm{mV})$ & $10.23 \pm 0.3$ & $6.3 \pm 0.26^{*}$ & $7.9 \pm 0.32$ & $8.6 \pm 0.21^{\#}$ \\
\hline
\end{tabular}

Results were presented as mean \pm standard error of mean.

${ }^{*} P<0.05$ versus control group; ${ }^{\#} P<0.05$ versus cisplatin + saline group.

TABLE 2: The effects of oxytocin on plasma MDA, GSH, and TNF- $\alpha$ levels in all groups.

\begin{tabular}{lcccc}
\hline & Normal control & Cisplatin + saline & Cisplatin $+80 \mu \mathrm{g} / \mathrm{kg}$ oxytocin & Cisplatin $+160 \mu \mathrm{g} / \mathrm{kg}$ oxytocin \\
\hline MDA $(\mathrm{nM})$ & $62.5 \pm 6.08$ & $128.6 \pm 9.09^{*}$ & $104.4 \pm 8.11^{\#}$ & $88.2 \pm 5.5^{\# \#}$ \\
GSH $(\mu \mathrm{M})$ & $19.4 \pm 3.6$ & $7.78 \pm 1.09^{*}$ & $11.2 \pm 1.9^{\# \#}$ & $14.8 \pm 1.6^{\# \#}$ \\
TNF- $\alpha(\mathrm{pg} / \mathrm{mL})$ & $23.2 \pm 2.6$ & $73.8 \pm 7.7^{*}$ & $43.5 \pm 7.9^{\#}$ & $31.6 \pm 5.8^{\# \#}$ \\
\hline
\end{tabular}

Results were presented as mean \pm SEM. ${ }^{*} P<0.001$, different from normal and cisplatin + saline groups; ${ }^{\#} P<0.05$ and ${ }^{\# \#} P<0.01$ different from cisplatin + saline groups.

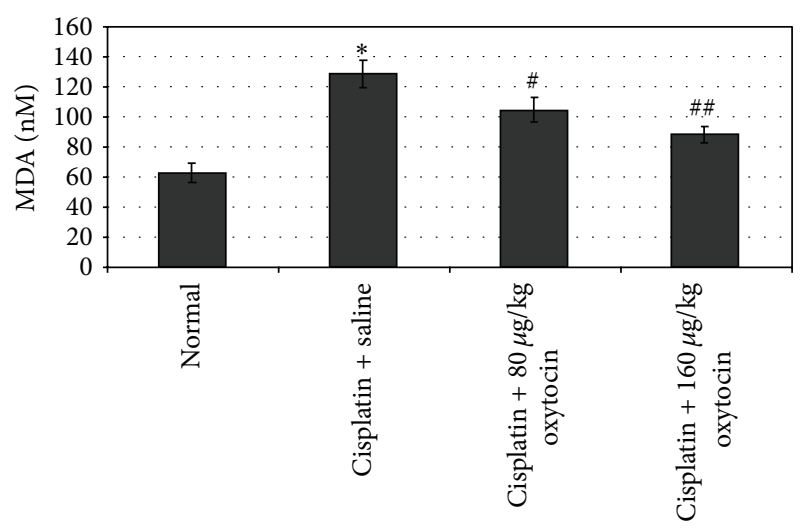

FIgURE 1: The effects of oxytocin on plasma MDA levels in all groups. Results were presented as mean \pm SEM. ${ }^{*} P<0.001$, different from normal and cisplatin + saline groups; ${ }^{\#} P<0.05$ and ${ }^{\# \#} P<0.01$, different from cisplatin + saline groups.

Moreover, CMAP amplitude increased in both OT groups, compared to the nontreated cisplatin-injected rats but this increase was statistically significant only in the rats that received $160 \mu \mathrm{g} / \mathrm{kg}$ of OT.

\subsection{Plasma Malondialdehyde, Glutathione, and Tumor Necro-} sis Factor- $\alpha$ Levels. The effects of OT on plasma MDA, GSH, and TNF- $\alpha$ levels in all groups are shown in Table 2.

Figure 1 shows the effects of OT on plasma MDA levels in the cisplatin-injected rats. The injection of the cisplatin resulted in a significant increase in plasma MDA levels compared to the control group (128.6 \pm 9.09 versus $62.5 \pm$ $6.08 \mathrm{nM} ; P<0.001)$. OT treatment significantly decreased mean MDA levels in a dose-dependent manner $(104.4 \pm$ $8.11 \mathrm{nM}$ for $80 \mu \mathrm{g} / \mathrm{kg}$ OT and $88.2 \pm 5.54 \mathrm{nM}$ for $160 \mu \mathrm{g} / \mathrm{kg}$ OT; $P<0.05$ and $P<0.01$, resp.).

Figure 2 demonstrates the effects of OT on plasma GSH levels in cisplatin-injected rats. Cisplatin administration significantly decreased plasma GSH levels, compared to the control group $(7.78 \pm 1.09$ versus $19.4 \pm 3.6 \mu \mathrm{M} ; P<0.001)$. OT treatment dose-dependently increased GSH levels (11.2 \pm

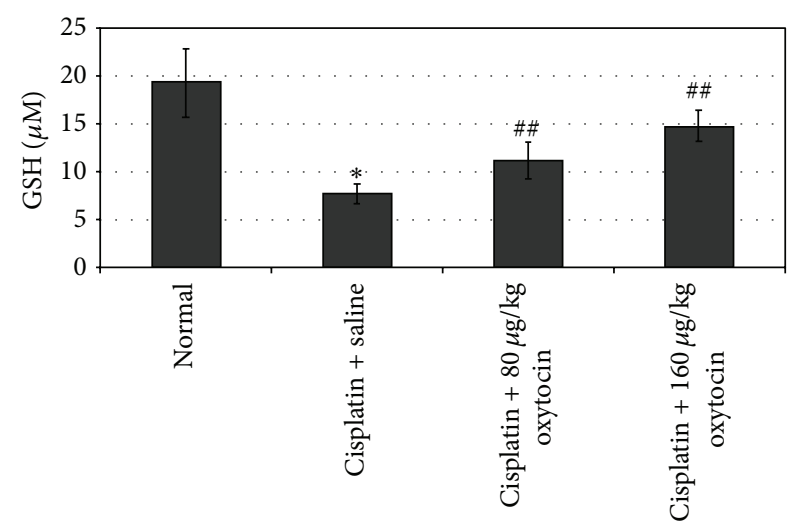

FIGURE 2: The effects of oxytocin on plasma GSH levels in all groups. Results were presented as mean \pm SEM. ${ }^{*} P<0.001$, different from normal and cisplatin + saline groups; ${ }^{\# \#} P<0.01$, different from cisplatin + saline groups.

$1.9 \mu \mathrm{M}$ for $80 \mu \mathrm{g} / \mathrm{kg}$ OT and $14.8 \pm 1.6 \mu \mathrm{M}$ for $160 \mu \mathrm{g} / \mathrm{kg} \mathrm{OT}$; $P<0.01)$.

Figure 3 shows the effects of OT on plasma TNF- $\alpha$ levels in cisplatin-injected rats. Cisplatin administration significantly increased plasma TNF- $\alpha$ levels, compared to the control group $(73.8 \pm 7.7$ versus $23.2 \pm 2.6 \mathrm{pg} / \mathrm{mL} ; P<0.001)$. OT treatment significantly decreased TNF- $\alpha$ levels and this decrease was more evident with the increased dose of OT $(43.5 \pm 7.9 \mathrm{pg} / \mathrm{mL}$ for $80 \mu \mathrm{g} / \mathrm{kg} \mathrm{OT}$ and $31.6 \pm 5.8 \mathrm{pg} / \mathrm{mL}$ for $160 \mu \mathrm{g} / \mathrm{kg}$ OT; $P<0.05$ and $P<0.01$, resp.).

\section{Discussion}

In this present study, we clearly demonstrated the protective effect of OT in cisplatin-induced neurotoxicity. To our knowledge, the prevention of neurotoxic effect of cisplatin with OT treatment has been demonstrated in this study for the first time. The neuroprotective effect seems to be associated with antioxidant (by the suppression of lipid peroxidation and increasing the antioxidative capacity) and anti-inflammatory (by decreasing the plasma TNF- $\alpha$ levels) activity of OT. 


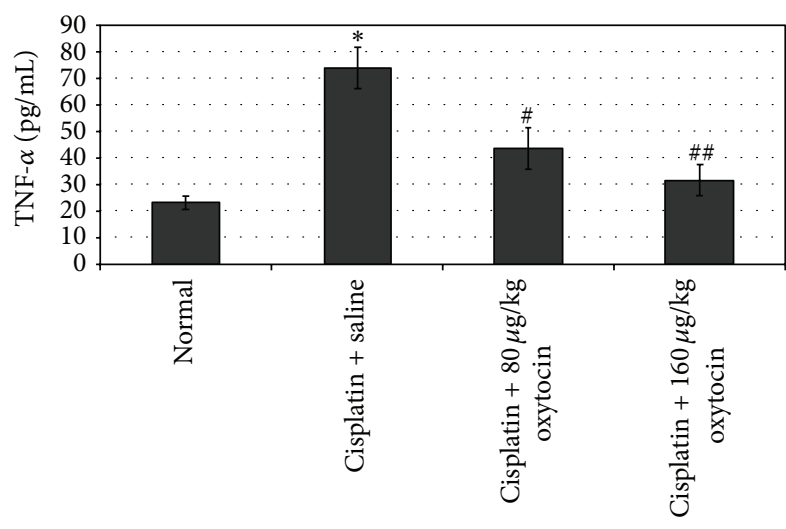

FIgURE 3: The effects of oxytocin on plasma TNF- $\alpha$ levels in all groups. Results were presented as mean \pm SEM. ${ }^{*} P<0.001$, different from normal and cisplatin + saline groups; ${ }^{\#} P<0.05$ and ${ }^{\# \#} P<$ 0.01 , different from cisplatin + saline groups.

There are several mechanisms proposed for cisplatininduced neurotoxicity. The drug accumulates especially in the dorsal root ganglia and causes nucleolar damage. Moreover, it affects Schwann cells, which have an important role in the nerve development and regeneration [25]. Another explanation for the mechanism of neuropathy is the binding of the cisplatin to DNA and inhibition of DNA synthesis [26]. Oxidative stress is another important mechanism. Cisplatin increases the production of free oxygen radicals and decreases the antioxidants, thus resulting in the deterioration of the oxidant/antioxidant balance and accumulation of reactive oxygen radicals in tissues [27]. Elevated free oxygen radicals interact with DNA and result in the production of 8hydroxyguanine (8-OH Gua), which is responsible for DNA damage [27]. Some studies also demonstrated that DNA damage and caspase activation played an essential role in cisplatin-induced toxicity $[28,29]$. Furthermore, proinflammatory cytokines such as TNF- $\alpha$, interleukin- (IL-) 1 , and IL-6 are induced with the nuclear factor- (NF-) kappa B activation and result in enhanced cisplatin toxicity [30, 31]. Apoptoses induced by hypoxia, inflammation, and accumulation of reactive oxygen free radicals in tissues are also basic mechanisms which play a role in cisplatin neurotoxicity.

The imbalance between oxidative and antioxidative mechanisms may play an important role in triggering axonal injury. Axonal transport is important for axonal integrity. Excessive reactive oxygen species (ROS) production causes distal axonal degeneration and interruption of axonal transportation. ROS can directly inhibit the axonal transportation in the early phase [32]. In addition to that, adenosine triphosphate (ATP) depletion and increased intra-axonal calcium levels caused by mitochondrial damage exacerbate the axonal damage. The decrease in the ATP levels inhibits the normal functions of the motor proteins [33].

Previous clinical and experimental studies demonstrated that antioxidant agents may prevent cisplatin-induced neurotoxicity $[15,19]$. OT is a secretory peptide hormone and a biochemical antioxidant. It is demonstrated that OT decreases the free oxygen radicals in the brain membranes, prevents low density lipoprotein oxidation, and inhibits lipid peroxidation [34]. When it is used at physiologic levels, OT may also decrease the acute inflammatory response, cytokine release, and oxidative stress. OT prevents lipid peroxidation on the cell membrane by scavenging the free oxygen radicals. Moreover, OT decreases lipid peroxidation, neutrophil infiltration, and serum TNF- $\alpha$ level in septic animal model [22]. Another human study demonstrated that OT decreases the levels of proinflammatory mediators such as TNF- $\alpha$, IL- 4 and 6 , macrophage inflammatory proteins $1 \mathrm{a}$ and $1 \mathrm{~b}$, monocyte chemoattractant protein-1, and vascular endothelial growth factor in lipopolysaccharide-induced inflammatory response and endotoxemia [35].

Our results revealed that the protective effect of OT in cisplatin-induced neuropathy may be due to its suppression on TNF- $\alpha$ production, lipid peroxidation, and elevation of antioxidant capacity. In this study, we used pharmacologic doses of OT ( 80 and $160 \mu \mathrm{g} / \mathrm{kg}$ ) based on previous studies demonstrating their protective effects $[36,37]$. We found that $160 \mu \mathrm{g} / \mathrm{kg}$ oxytocin dose was more effective in the prevention of cisplatin-induced neurotoxicity.

In conclusion, this is the first study which demonstrates that OT has a protective effect in cisplatin-induced neurotoxicity via increasing the endogenous antioxidants and decreasing the lipid peroxidation and inflammation. Based on these findings, OT may be considered as a potential agent that can be used for the prevention of cisplatin-induced neurotoxicity. However, new experimental and clinical studies are required for the clinical application of this treatment modality for preventing the neurotoxicity in cancer patients.

\section{Conflict of Interests}

The authors declare that there is no conflict of interests regarding the publication of this paper.

\section{References}

[1] J. E. Mollman, "Cisplatin neurotoxicity," The New England Journal of Medicine, vol. 322, no. 2, pp. 126-127, 1990.

[2] G. Cavaletti, G. Tredici, P. Marmiroli, M. G. Petruccioli, I. Barajon, and D. Fabbrica, "Morphometric study of the sensory neuron and peripheral nerve changes induced by chronic cisplatin (DDP) administration in rats," Acta Neuropathologica, vol. 84, no. 4, pp. 364-371, 1992.

[3] E. E. M. Brouwers, A. D. R. Huitema, W. Boogerd, J. H. Beijnen, and J. H. M. Schellens, "Persistent neuropathy after treatment with cisplatin and oxaliplatin," Acta Oncologica, vol. 48, no. 6, pp. 832-841, 2009.

[4] L. Kelland, "The resurgence of platinum-based cancer chemotherapy," Nature Reviews Cancer, vol. 7, no. 8, pp. 573-584, 2007.

[5] B. Orhan, S. Yalcin, G. Nurlu, D. Zeybek, and S. Muftuoglu, "Erythropoietin against cisplatin-induced peripheral neurotoxicity in rats," Medical Oncology, vol. 21, no. 2, pp. 197-203, 2004.

[6] A. Pace, D. Giannarelli, E. Galiè et al., "Vitamin E neuroprotection for cisplatin neuropathy: a randomized, placebo-controlled trial," Neurology, vol. 74, no. 9, pp. 762-766, 2010.

[7] V. Carozzi, A. Chiorazzi, A. Canta et al., "Effect of the chronic combined administration of cisplatin and paclitaxel in a rat 
model of peripheral neurotoxicity," European Journal of Cancer, vol. 45, no. 4, pp. 656-665, 2009.

[8] A. Krarup-Hansen, S. Helweg-Larsen, H. Schmalbruch, M. Rørth, and C. Krarup, "Neuronal involvement in cisplatin neuropathy: prospective clinical and neurophysiological studies," Brain, vol. 130, no. 4, pp. 1076-1088, 2007.

[9] M. I. Turan, A. Cayir, N. Cetin, H. Suleyman, I. S. Turan, and H. Tan, "An investigation of the effect of thiamine pyrophosphate on cisplatin-induced oxidative stress and DNA damage in rat brain tissue compared with thiamine: thiamine and thiamine pyrophosphate effects on cisplatin neurotoxicity," Human and Experimental Toxicology, vol. 33, no. 1, pp. 14-21, 2014.

[10] S.-J. Kim, J.-Y. Lim, J. N. Lee et al., "Activation of $\beta$-catenin by inhibitors of glycogen synthase kinase-3 ameliorates cisplatininduced cytotoxicity and pro-inflammatory cytokine expression in HEI-OCl cells," Toxicology, vol. 320, no. 1, pp. 74-82, 2014.

[11] E. W. Englander, "DNA damage response in peripheral nervous system: coping with cancer therapy-induced DNA lesions," DNA Repair, vol. 12, no. 8, pp. 685-690, 2013.

[12] J. S. Gill and A. J. Windebank, "Cisplatin-induced apoptosis in rat dorsal root ganglion neurons is associated with attempted entry into the cell cycle," The Journal of Clinical Investigation, vol. 101, no. 12, pp. 2842-2850, 1998.

[13] L. M. Mendonça, C. da Silva Machado, C. C. Teixeira, L. A. de Freitas, L. Bianchi Mde, and L. M. Antunes, "Curcumin reduces cisplatin-induced neurotoxicity in NGF-differentiated PC12 cells," Neurotoxicology, vol. 34, pp. 205-211, 2013.

[14] A. Pace, A. Savarese, M. Picardo et al., "Neuroprotective effect of vitamin E supplementation in patients treated with cisplatin chemotherapy," Journal of Clinical Oncology, vol. 21, no. 5, pp. 927-931, 2003.

[15] M. A. Rezvanfar, M. A. Rezvanfar, A. R. Shahverdi et al., "Protection of cisplatin-induced spermatotoxicity, DNA damage and chromatin abnormality by selenium nano-particles," Toxicology and Applied Pharmacology, vol. 266, no. 3, pp. 356-365, 2013.

[16] S. Tuncer, N. Dalkilic, M. A. Dunbar, and B. Keles, "Comparative effects of alpha lipoic acid and melatonin on cisplatininduced neurotoxicity," International Journal of Neuroscience, vol. 120, no. 10, pp. 655-663, 2010.

[17] M. A. Valentovic, J. G. Ball, J. M. Brown et al., "Resveratrol attenuates cisplatin renal cortical cytotoxicity by modifying oxidative stress," Toxicology in Vitro, vol. 28, no. 2, pp. 248-257, 2014.

[18] G. Gimpl and F. Fahrenholz, "The oxytocin receptor system: Structure, function, and regulation," Physiological Reviews, vol. 81, no. 2, pp. 679-683, 2001.

[19] D.-X. Tan, L. C. Manchester, M. P. Terron, L. J. Flores, and R. J. Reiter, "One molecule, many derivatives: a never-ending interaction of melatonin with reactive oxygen and nitrogen species?" Journal of Pineal Research, vol. 42, no. 1, pp. 28-42, 2007.

[20] M. Jankowski, D. Wang, F. Hajjar, S. Mukaddam-Daher, S. M. McCann, and J. Gutkowska, "Oxytocin and its receptors are synthesized in the rat vasculature," Proceedings of the National Academy of Sciences of the United States of America, vol. 97, no. 11, pp. 6207-6211, 2000.

[21] G. Gimpl and F. Fahrenholz, "The oxytocin receptor system: structure, function, and regulation," Physiological Reviews, vol. 81, no. 2, pp. 629-683, 2001.
[22] O. Erbaş, F. Oltulu, and D. Taşkiran, "Amelioration of rotenoneinduced dopaminergic cell death in the striatum by oxytocin treatment," Peptides, vol. 38, no. 2, pp. 312-317, 2012.

[23] K. A. Wichterman, A. E. Baue, and I. H. Chaudry, "Sepsis and septic shock-a review of laboratory models and a proposal," Journal of Surgical Research, vol. 29, no. 2, pp. 189-201, 1980.

[24] G. L. Ellman, "Tissue sulfhydryl groups," Archives of Biochemistry and Biophysics, vol. 82, no. 1, pp. 70-77, 1959.

[25] J. M. Garcia, J. P. Cata, P. M. Dougherty, and R. G. Smith, "Ghrelin prevents cisplatin-induced mechanical hyperalgesia and cachexia," Endocrinology, vol. 149, no. 2, pp. 455-460, 2008.

[26] K. Tomiwa, C. Nolan, and J. B. Cavanagh, "The effects of cisplatin on rat spinal ganglia: a study by light and electron microscopy and by morphometry," Acta Neuropathologica, vol. 69, no. 3-4, pp. 295-308, 1986.

[27] Y. Kawai, T. Nakao, N. Kunimura, Y. Kohda, and M. Gemba, "Relationship of intracellular calcium and oxygen radicals to cisplatin-related renal cell injury," Journal of Pharmacological Sciences, vol. 100, no. 1, pp. 65-72, 2006.

[28] M. E. I. Leibbrandt, G. H. I. Wolfgang, A. L. Metz, A. A. Ozobia, and J. R. Haskins, "Critical subcellular targets of cisplatin and related platinum analogs in rat renal proximal tubule cells," Kidney International, vol. 48, no. 3, pp. 761-770, 1995.

[29] M. W. van Ruijven, J. C. de Groot, S. F. Klis, and G. F. Smoorenburg, "The cochlear targets of cisplatin: an electrophysiological and morphological time-sequence study," Hearing Research, vol. 205, no. 1-2, pp. 241-248, 2005.

[30] G. P. Kaushal, V. Kaushal, X. Hong, and S. V. Shah, "Role and regulation of activation of caspases in cisplatin-induced injury to renal tubular epithelial cells," Kidney International, vol. 60, no. 5, pp. 1726-1736, 2001.

[31] H. So, H. Kim, J.-H. Lee et al., "Cisplatin cytotoxicity of auditory cells requires secretions of proinflammatory cytokines via activation of ERK and NF- $\kappa \mathrm{B}$," Journal of the Association for Research in Otolaryngology, vol. 8, no. 3, pp. 338-355, 2007.

[32] C. Fang, D. Bourdette, and G. Banker, "Oxidative stress inhibits axonal transport: implications for neurodegenerative diseases," Molecular Neurodegeneration, vol. 7, no. 1, article 29, 2012.

[33] K. J. Verhey, N. Kaul, and V. Soppina, "Kinesin assembly and movement in cells," Annual Review of Biophysics, vol. 40, no. 1, pp. 267-288, 2011.

[34] B. Moosmann and C. Behl, "Secretory peptide hormones are biochemical antioxidants: structure-activity relationship," Molecular Pharmacology, vol. 61, no. 2, pp. 260-268, 2002.

[35] M. Clodi, G. Vila, R. Geyeregger et al., "Oxytocin alleviates the neuroendocrine and cytokine response to bacterial endotoxin in healthy men," The American Journal of PhysiologyEndocrinology and Metabolism, vol. 295, no. 3, pp. 686-691, 2008.

[36] M. Petersson, T. Lundeberg, A. Sohlström, U. Wiberg, and K. Uvnäs-Moberg, "Oxytocin increases the survival of musculocutaneous flaps," Naunyn-Schmiedeberg's Archives of Pharmacology, vol. 357, no. 6, pp. 701-704, 1998.

[37] O. Erbaş, A. M. Ergenoglu, A. Akdemir, A. Ö. Yeniel, and D. Taskiran, "Comparison of melatonin and oxytocin in the prevention of critical illness polyneuropathy in rats with experimentally induced sepsis," Journal of Surgical Research, vol. 183, no. 1, pp. 313-320, 2013. 


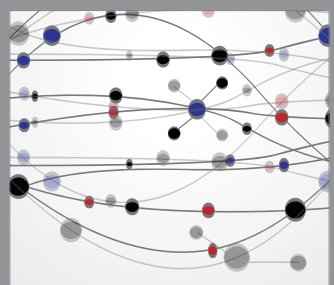

The Scientific World Journal
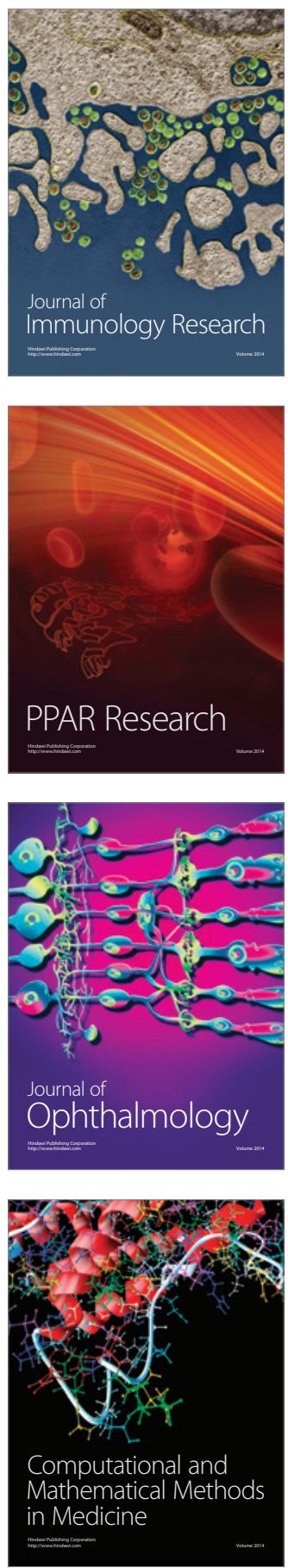

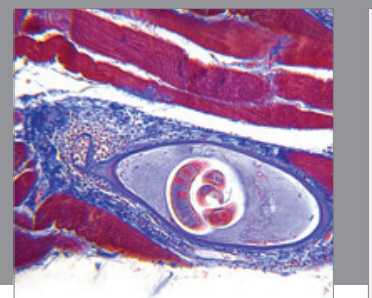

Gastroenterology

Research and Practice
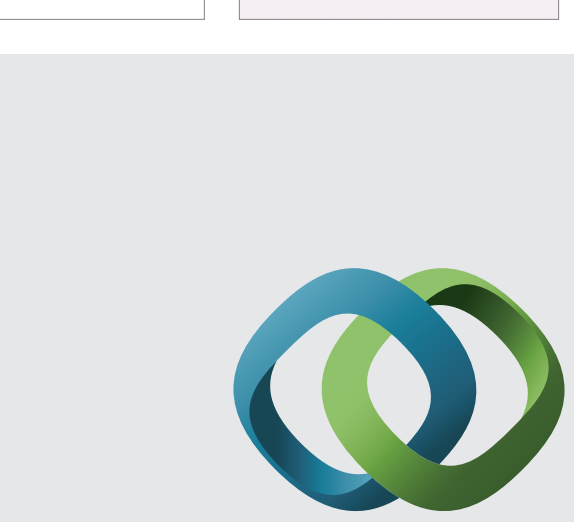

\section{Hindawi}

Submit your manuscripts at

http://www.hindawi.com
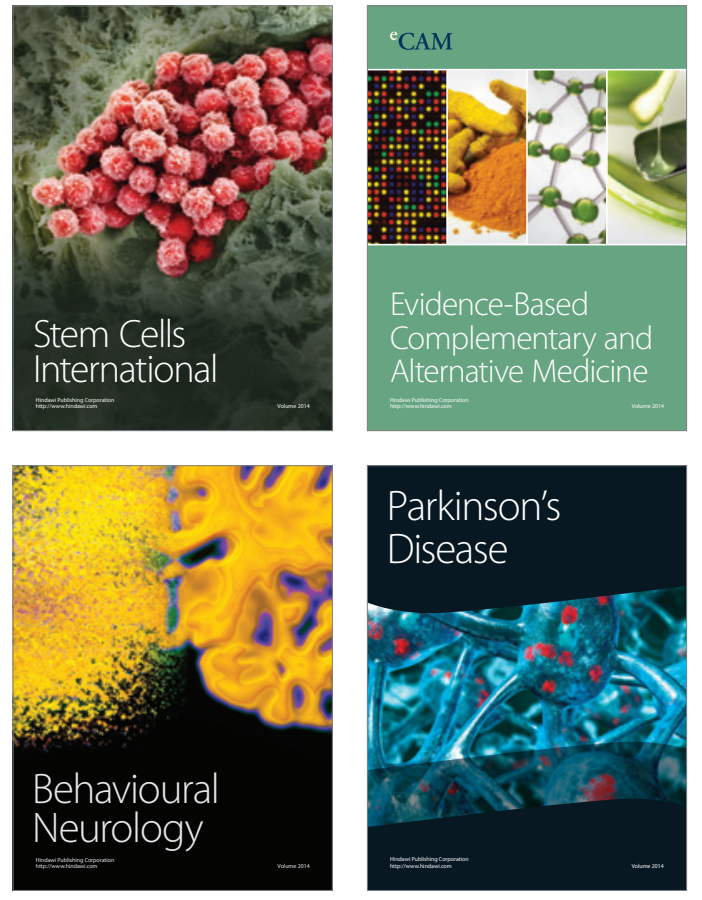
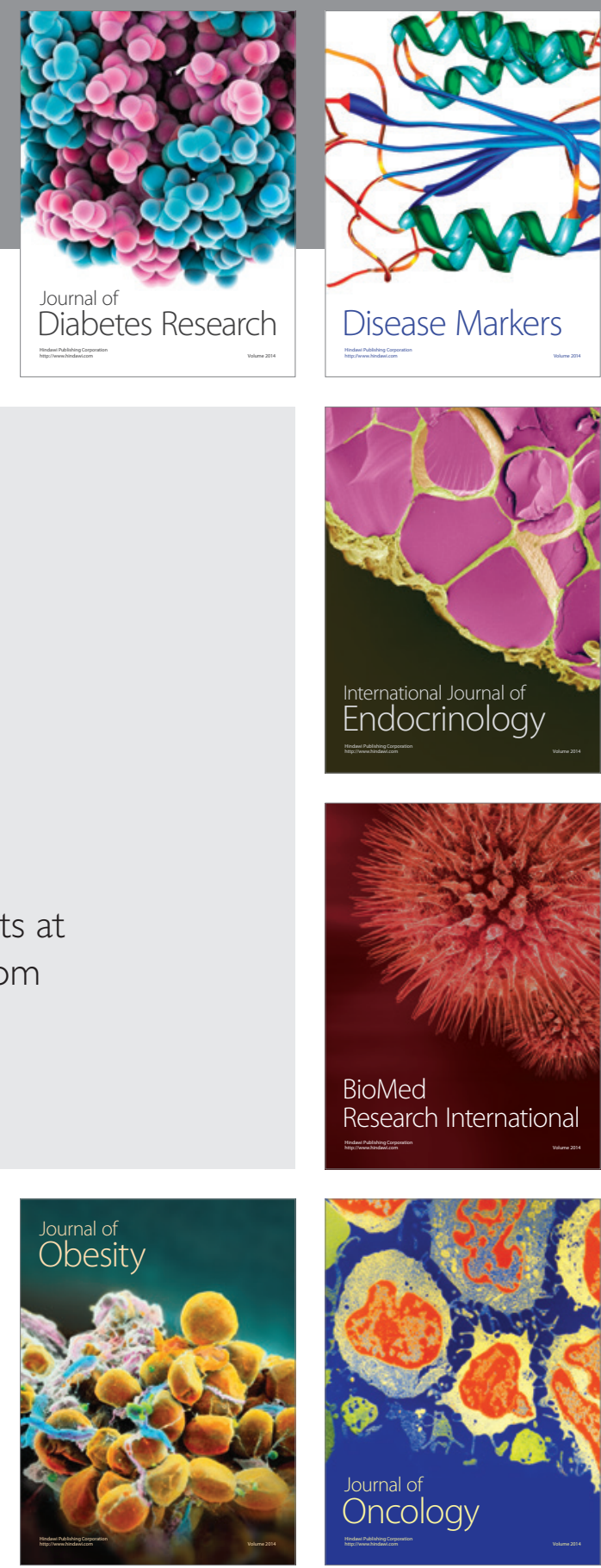

Disease Markers
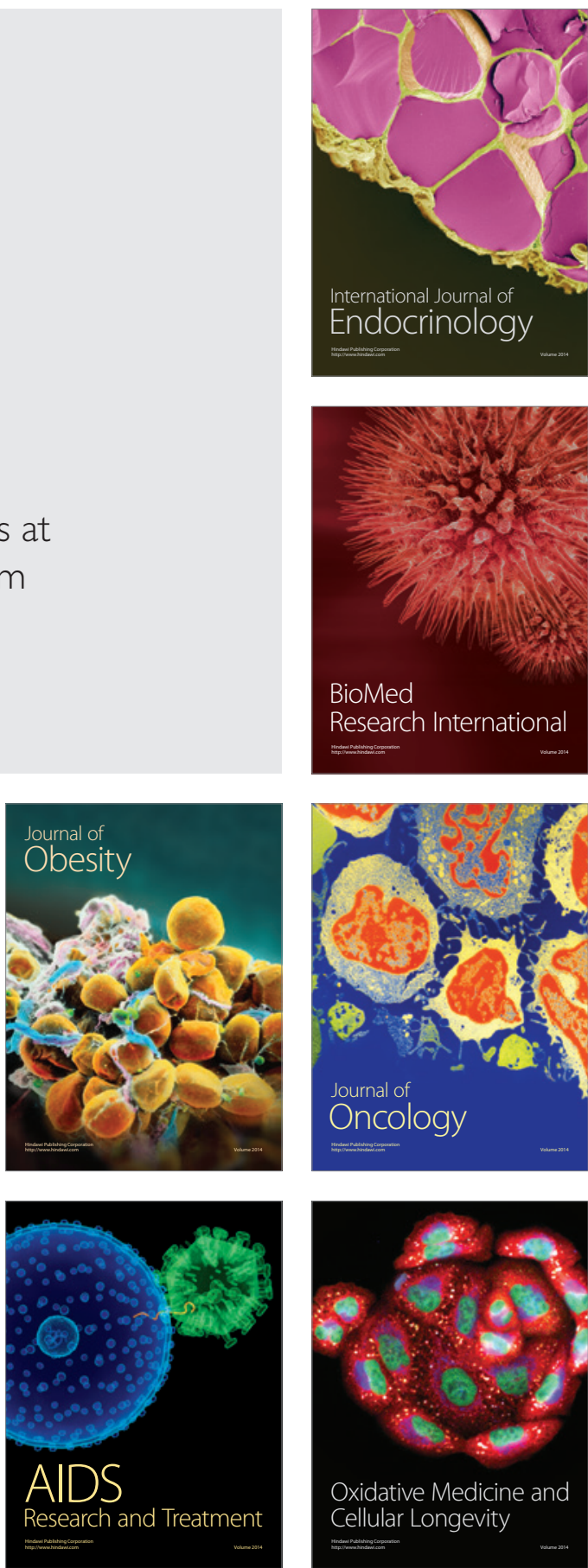